\title{
MULTISTAGE DILUTE ACID LEACHING OF A MEDIUM GRADE IRON ORE TO SUPER-CONCENTRATE
}

\author{
A.A. Adeleke, J.O. Olawale", K.M. Oluwasegun, M.D. Shittu, A.D. Azeez, O. Falana \\ Obafemi Awolowo University, Department of Materials Science and Engineering, \\ Ile-Ife, Nigeria
}

(Received: October 18, 2013; Accepted: July 7, 2014)

\begin{abstract}
The phosphorous laden Koton Karfe iron ore is a medium grade iron ore deposit in Nigeria that can be upgraded as a super-concentrate for use at the Aladja Steel Midrex plant. The $75 \mu \mathrm{m}$ size sample fraction of the ore was preconcentrated with shaking table and leached in the oven at atmospheric pressure with dilute hydrochloric acid in single and multistage leaching sequences of $\mathrm{H}_{2} \mathrm{O}-\mathrm{HCl}-\mathrm{H}_{2} \mathrm{O}$ and $\mathrm{HCl}-\mathrm{H}_{2} \mathrm{O}-\mathrm{H}_{2} \mathrm{O}$. The as-received, as-tabled and asleached samples were then subjected to $X$-ray fluorescence and microscopic analyses. The results obtained showed that the $\mathrm{H}_{2} \mathrm{O}-\mathrm{HCl}-\mathrm{H}_{2} \mathrm{O}$ route produced a higher grade concentrate that assayed $68.54 \% \mathrm{Fe}$ indicating about $58 \%$ upgrade in iron content; while the phosphorus and sulphur contents were reduced by about 77 and $99.6 \%$ respectively. In addition, the silicon, manganese, and titanium contents were drastically reduced, while potassium was completely eliminated. The upgrade of iron content in the ore to $68.54 \%$ and the drastic reduction in phosphorous and sulphur contents has thus rendered the Koton Karfe iron ore suitable for use as a super concentrate for the Aladja steel plant direct reduction iron making process.
\end{abstract}

Key words: iron ore, pre-concentrate, leaching, multistage leaching, super-concentrate.

\section{Introduction}

Iron ores are rocks and minerals from which metallic iron can be economically extracted. The ores are usually rich in iron oxides and vary in colour from dark grey, bright yellow, deep purple, to rusty red. The iron itself is usually found in the form of magnetite $\left(\mathrm{Fe}_{3} \mathrm{O}_{4}\right.$ containing $\left.72 \% \quad \mathrm{Fe}\right)$, hematite $\left(\mathrm{Fe}_{2} \mathrm{O}_{3}\right.$ containing $\left.70 \% \mathrm{Fe}\right)$, goethite $(\mathrm{FeO}(\mathrm{OH})$ containing $62.5 \% \mathrm{Fe})$, limonite $\left(\mathrm{Fe}_{2} \mathrm{O}_{3} \cdot 3 \mathrm{H}_{2} \mathrm{O}\right)$ containing variable amount of $\mathrm{Fe})$, Siderite $\left(\mathrm{FeCO}_{3}\right.$ containing $48.3 \%$ of $\left.\mathrm{Fe}\right)$, pyrrhotite (FeS containing $61.5 \%$ of $\mathrm{Fe}$ ) and pyrite $\left(\mathrm{FeS}_{2}\right.$ containing $46.7 \%$ of $\left.\mathrm{Fe}\right)$. Ores carrying very high quantities of hematite or magnetite (greater than 60\% iron) are known as natural ore [1].

${ }^{\#}$ Corresponding author: Amir.khademian@mi.iut.ac.ir
The estimate of workable iron ore deposits in Nigeria is in excess of 2.5 billion tons most of which belong to hematite, hematitemagnetite, hematite-goethite and sideritegoethite grades [2]. The Nigeria iron deposit and their locations are as presented in Table 1, while the geographical location of the Koton Karfe iron is indicated in Fig. 1.

From this table, it can be seen that Agbaja, Koton Karfe and Bassa Nge deposits have the highest contents of iron. These deposits also account for over 1 billion metric tons reserve of iron ore in Nigeria [2]. However, their high phosphorus, potassium and silicon contents, and fine-grained texture constitute the major problems for their utilization in the blast furnace or direct reduction process [3]. 


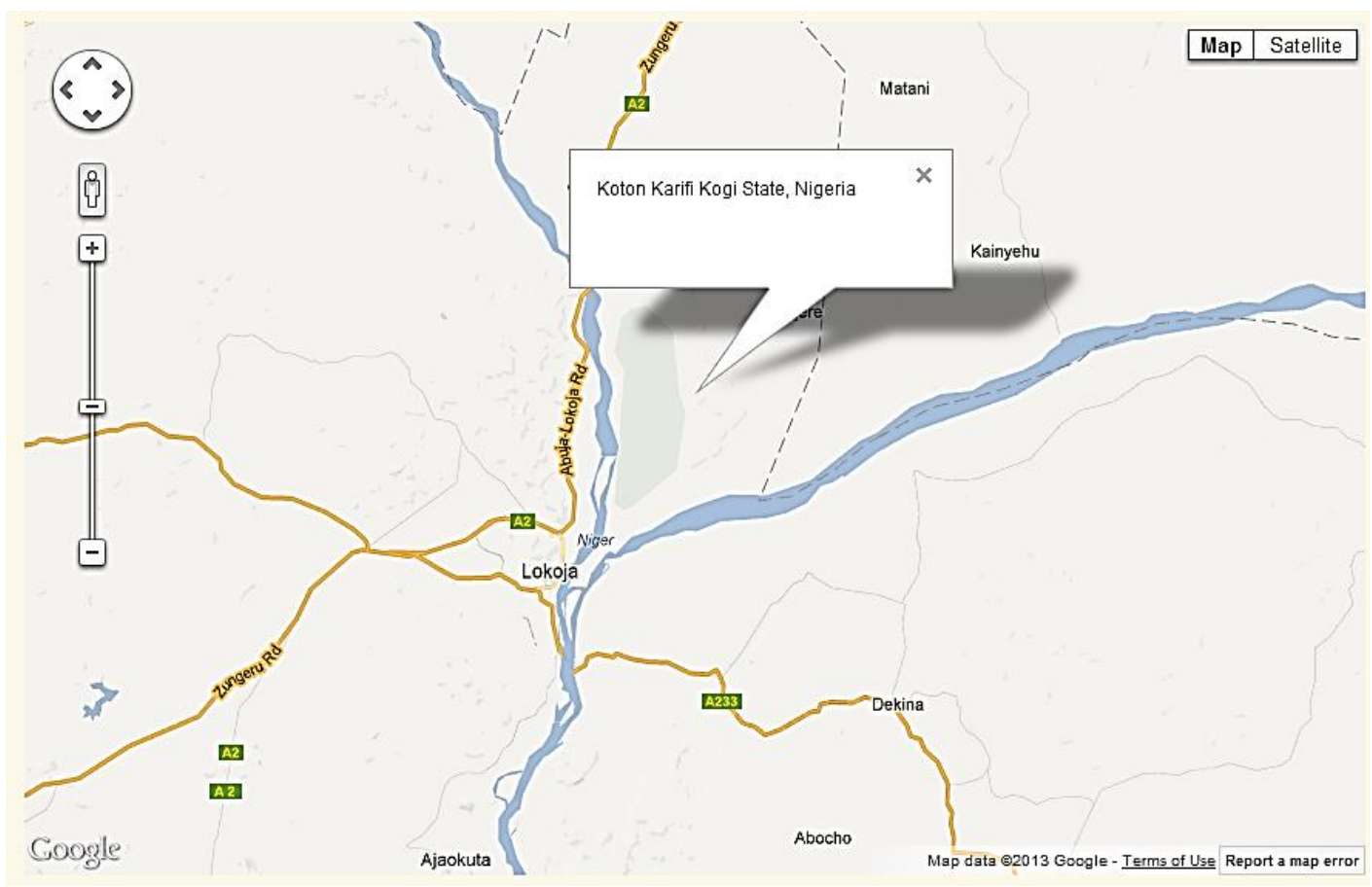

Figure 1. Geographic Map of Koton Karfe Area

Table 1. Nigerian iron ore deposits and their locations

\begin{tabular}{|c|l|l|l|}
\hline S/N & Deposit & Location & $\% \mathrm{Fe}$ \\
\hline 1 & Itakpe & Kogi & $32-39$ \\
\hline 2 & Oshokoshoko & Kwara & $28-38$ \\
\hline 3 & Ajabanoko & Kwara & $37-43$ \\
\hline 4 & Muro & Nassarawa & $25-38$ \\
\hline 5 & Agbaja & Kogi & $43-49$ \\
\hline 6 & Koton Karfe & Kogi & $43-49$ \\
\hline 7 & Bassa Nge & Kogi & $43-49$ \\
\hline 8 & Akiona & Kwara & $41-47$ \\
\hline 9 & Tajimi & Kwara & $39-43$ \\
\hline 10 & Rishi & Bauchi & $10-19$ \\
\hline 11 & Ayiwawa & Bauchi & $6-23$ \\
\hline 12 & Karfa & Borno & $34-45$ \\
\hline 13 & Sokoto & Sokoto & $27-30$ \\
\hline
\end{tabular}

Source: Uwadiale, 1984 [4]

However, the need for constant and stable supply of iron ore super concentrates to the
Aladja Steel Midrex plant necessitates further studies to upgrade these iron ore deposits. Hence, the aim of this research work is to upgrade the Koton Karfe iron ore from these deposits to a super-concentrate through multistage leaching using dilute hydrochloric acid.

\section{Materials and methods}

\subsection{Material}

The sample of Koton Karfe iron ore used for this research was obtained from the National Metallurgical Development Centre, Jos, Nigeria. About $10 \mathrm{~kg}$ of the iron ore was selected from the bulk sample sourced at a depth of 4.0 to $5.5 \mathrm{~m}$. The chemical composition of this ore as obtained from XRay Fluorescence Spectrometer is presented in Table 2. 
Table 2. Elemental composition of as-received iron ore

\begin{tabular}{llllllllll}
\hline $\mathbf{F e}$ & $\mathbf{S i}$ & $\mathbf{M n}$ & $\mathbf{T i}$ & $\mathbf{K}$ & $\mathbf{C a}$ & $\mathbf{N a}$ & $\mathbf{M g}$ & $\mathbf{P}$ & $\mathbf{S}$ \\
\hline 43.45 & 25.85 & 0.8215 & 0.261 & 0.3272 & 0.6298 & 0.4092 & 0.4263 & 0.0246 & 0.098 \\
\hline
\end{tabular}

\subsection{Sample Preparation}

The ore was broken into smaller sizes that could be fed into the jaw crusher using a sledge hammer. Crushing was done using the laboratory jaw crusher (BD 1028), roll crusher (168FD39) and cone crusher (HZ24KL) at the National Metallurgical Development Centre, Jos. Representative Sample was obtained through cone and quartering. Thereafter, the sample was air dried for about 48 hours to remove surface moisture in the ore.

\subsection{Sieve Analysis}

The ore was screened in accordance with ASTM E-11 standard procedure. The sieves selected for the test were arranged in a stack, with the coarsest sieve on the top and the finest at the bottom. A tight-fitting pan was placed under the bottom sieve to receive the final undersize and a lid was placed on top of the coarsest sieve to prevent escape of the sample. About $250 \mathrm{~g}$ of the sample was weighed and placed in the uppermost coarsest sieve, and the nest was then placed in a sieve shaker which vibrates the material in a vertical plane. After shaking for about 30 minutes, the nest was removed from the shaker and the amount of material retained on each sieve was weighed and recorded as retained size.

\subsection{Tabling}

About $250 \mathrm{~g}$ of the iron ore was mixed with water to form slurry. The slurry was charged into the table via the feeding point together with wash water. As the slurry spreads out across the inclined surface of the table the particles were separated on the basis of particle specific gravity, with denser particles moving along the top of the flowing film to discharge off at the far end as the concentrate, while lighter particles moved down the inclined slope of the table to discharge at the bottom as tailings. The particle separation was assisted by the backward and forward motion (strokes) of the table, the tilt (both longitudinally and laterally), the wash water applied along the length of the table and the riffles.

\subsection{Leaching}

The single stage leaching was carried out with about $1 \mathrm{~g}$ of the pre-concentrated samples (subjected to 5 minutes preliminary agitation in a $250 \mathrm{ml}$ beaker and thereafter covered with aluminium foil) at 0.25 and $0.75 \mathrm{M} \mathrm{HCl}$ in a $2^{3}$ factorial design with temperatures of 30 and $90^{\circ} \mathrm{C}$ and leaching contact times of 20 and 80 minutes at atmospheric pressure. Further single stage leaching were also conducted at 0.875 and $1 \mathrm{M}$ $\mathrm{HCl}$ at a temperature of $90^{\circ} \mathrm{C}$ and leaching contact time of 80 minutes to determine the optimal hydrochloric acid concentration. The leaching was further carried out with water only in a $2^{2}$ factorial design at 30 and $90^{\circ} \mathrm{C}$, and 20 and 80 minutes contact times. The oven leached sample was then filtered into a conical flask using the Whatman filter. The residue was collected, oven dried at about $90^{\circ} \mathrm{C}$ and re-weighed. The difference in weight was noted for determining the fraction of the iron ore that has been dissolved. The solid residue was the product concentrate while the solution contained the dissolved undesirable gangue. The efficiency of $\mathrm{HCl}$ dissolution of $\mathrm{Fe}$ oxide is ascribed to the formation of ferric chloride as described by the chemical reaction below: 
$\mathrm{Fe}_{2} \mathrm{O}_{3}+6 \mathrm{H}^{+} \mathrm{Cl}^{-}=2 \mathrm{FeCl}_{3}+3 \mathrm{H}_{2} \mathrm{O}$

For the multistage leaching, the procedure described in single stage leaching was repeated in three steps but at a temperature of $90^{\circ} \mathrm{C}$ and 80 minutes contact time. In the first stage, the sample was leached with water, then with $0.875 \mathrm{M}$ hydrochloric acid and the final stage water leaching to clean the iron ore in the $\mathrm{H}_{2} \mathrm{O}-\mathrm{HCl}-\mathrm{H}_{2} \mathrm{O}$ leaching sequence. The three stage leaching procedure was repeated but in the sequence $\mathrm{HCl}-\mathrm{H}_{2} \mathrm{O}-\mathrm{H}_{2} \mathrm{O}$. The elemental analysis of final residue of the two three stage routes that gave the highest percentage dissolution of gangue minerals was taken from X-ray fluorescence spectrometer and its photomicrography from electron microscope. The elemental analysis and photomicrograph of as-received and tabled concentrate were also taken.

\subsection{Elemental Analysis}

About $0.5 \mathrm{~g}$ of as-received, tabled and leached samples was pressed to obtain cylindrical pellets. The pellet were then mounted on the sample holder of the X-ray fluorescence spectrometer machine (Model HERZOG PW 1606) and were irradiated for 20 minutes at a fixed $\mathrm{X}$-ray tube operating condition of $25 \mathrm{KV}$ and $6 \mathrm{Ma}$. Afterwards the results of elemental composition of ore concentrate in as-received, tabled and leached conditions were displayed on the desktop computer which was connected to the X-ray fluorescence spectrometer.

\subsection{Photomicrography}

This test was carried-out to determine the liberation size of the iron ore and the concentration of iron content in as-received, tabling and leach sample. The iron ore sample fraction was prepared by mixing araldite (resin) and araldite (hardener) thoroughly together in equal proportion in a square container. Thereafter, about $0.5 \mathrm{~g}$ of the screened iron ore was poured into the mixture that has been prepared and this was mixed together. The whole mixture was then placed on a glass slide having a rectangular shape and then left on a table for about an hour to get hardened. After hardening, a grinding wheel machine Model No. BD112 was used to thin the sample on the glass slide, while the finishing thinning to the appropriate diameter was carried out on a lapping/thinning plate which has been sprayed with silicon carbide. Due to the presence of some percentage of water, the sample was heated on a hotplate for about 5 minutes for drying. After the drying, Canada balsam paste was applied on the sample surface, then, a cover slip was then used to cover the surface for preservation. Thereafter, the slide prepared as described above was viewed with Phillips light transmission microscope Model No. 682 .

The magnification was set at $\times 400$ for proper viewing and the microscope was adjusted to get the best possible view and afterwards the view was taken using a digital camera.

\section{Results and discussion}

Screen distribution analysis shows that about $99.37 \%$ of the ore passed through the largest sieve size $(2300 \mu \mathrm{m}$ sieve) while about $1.96 \%$ passed through the entire sieve size (Figure 2). The light transmission micrograph reveals that the iron ore concentration increases as the percentage resultant weight decreases (Figure 3). The concentration of iron ore is the least in $1180 \mu \mathrm{m}$ sieve size where the percentage resultant weight is the highest $(25.53 \%)$ and the highest in $75 \mu \mathrm{m}$ sieve size where it is the least. Hence, the liberation size (the size to which the iron ore can be economically grinded to ensure effective beneficiation) was determined to be $75 \mu \mathrm{m}$. 


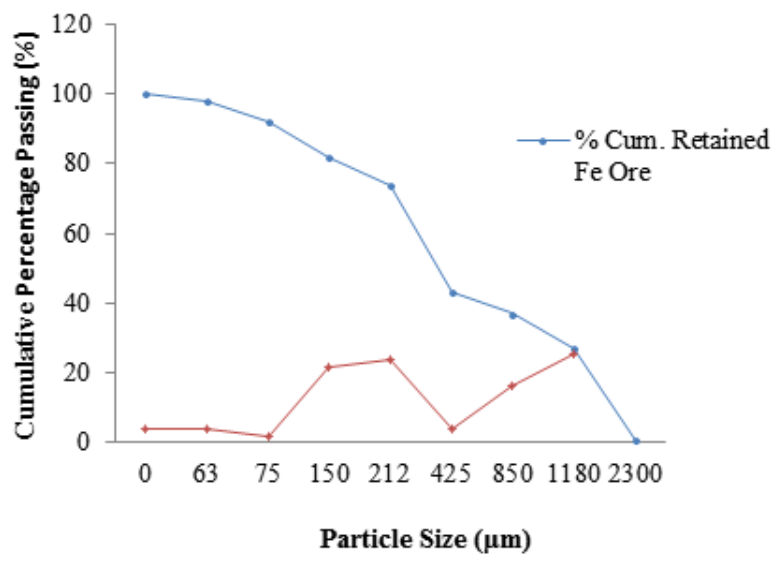

Figure 2. Particle size distribution

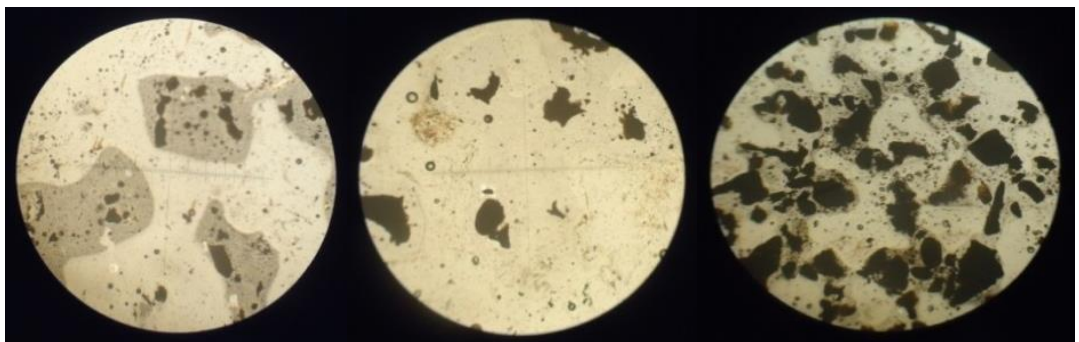

a) Sample from $2.300 \mathrm{~mm}$ sieve size b) Sample from $1.180 \mathrm{~mm}$ sieve size c) Sample from 0.850 $\mathrm{mm}$ sieve size

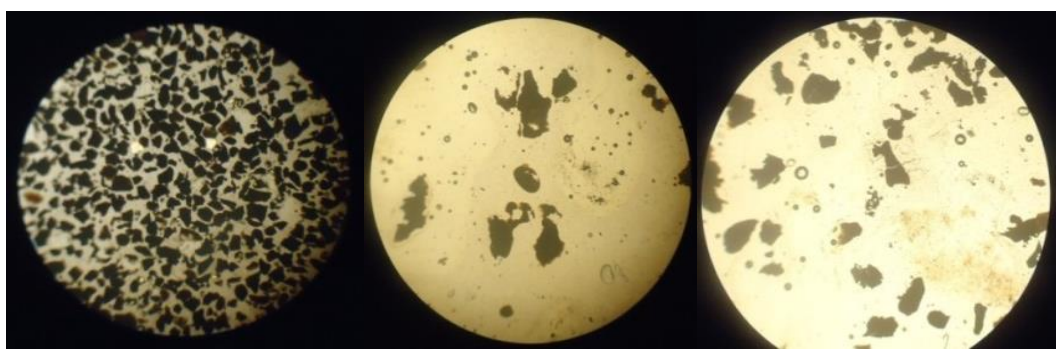

d) Sample from $0.425 \mathrm{~mm}$ sieve size e) Sample from $0.212 \mathrm{~mm}$ sieve size f) Sample from $0.150 \mathrm{~mm}$ sieve size

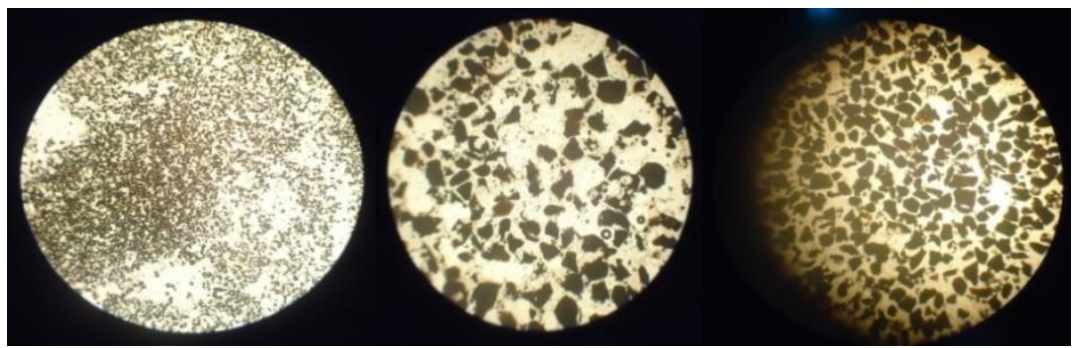

g) Sample from $0.075 \mathrm{~mm}$ sieve size h) Sample from $0.063 \mathrm{~mm}$ sieve size i) Sample from pan

Figure 3. Photomicrograph of iron ore on each sieve size (Mag. $\times 400)$ 
Table 3 presents the results of single stage leaching which indicated that the weight loss obtained generally increased with increasing molar concentration.

Table 3. Result of single stage atmospheric oven leaching

\begin{tabular}{cccc}
\hline $\begin{array}{c}\text { Concentration } \\
(\mathbf{M})\end{array}$ & $\begin{array}{c}\text { Temperature } \\
\left({ }^{\circ} \mathbf{C}\right)\end{array}$ & $\begin{array}{c}\text { Time } \\
(\mathbf{m i n})\end{array}$ & $\begin{array}{c}\text { Weight } \\
\text { loss } \\
(\boldsymbol{\%})\end{array}$ \\
\hline 0.25 & 30 & 20 & 0.8 \\
0.25 & 30 & 80 & 1.8 \\
0.25 & 90 & 20 & 1.8 \\
0.25 & 90 & 80 & 2.2 \\
0.75 & 30 & 20 & 1.0 \\
0.75 & 30 & 80 & 2.5 \\
0.75 & 90 & 20 & 1.2 \\
0.75 & 90 & 80 & 3.5 \\
0.875 & 90 & 80 & 4.7 \\
1.00 & 90 & 80 & 2.8 \\
$\mathrm{H}_{2} \mathrm{O}$ & 30 & 20 & 0.6 \\
$\mathrm{H}_{2} \mathrm{O}$ & 30 & 80 & 1.1 \\
$\mathrm{H}_{2} \mathrm{O}$ & 90 & 20 & 0.8 \\
$\mathrm{H}_{2} \mathrm{O}$ & 90 & 80 & 1.8 \\
\hline
\end{tabular}

The results obtained for the $2^{3}$ factorial designed single stage leaching showed that the lowest and highest losses (of 0.8 and 3.5\%) occurred at hydrochloric acid molar concentration, leaching temperature, contact time of $0.25 \mathrm{M}, 90^{\circ} \mathrm{C}, 20$ minutes and $0.75 \mathrm{M}$, $90^{\circ} \mathrm{C}, 80$ minutes; respectively. Further leaching to determine the optimal molar concentration showed that leaching at $0.875 \mathrm{M}, 90^{\circ} \mathrm{C}, 80$ minutes and $1 \mathrm{M}, 90^{\circ} \mathrm{C}, 80$ minutes produced 4.7 and $2.8 \%$ weight losses, respectively. The results obtained for the multistage leaching thus indicate that the weight loss of the iron ore generally increased with increasing molar concentration, temperature and leaching contact time. However, further leaching at higher molar concentrations showed that the optimal concentration occurred at $0.875 \mathrm{M}$ beyond which a decrease in weight loss set in. The decrease in weight loss may be due to the precipitation of some insoluble reaction products. The leaching with water only as a control step at the same temperature and contact time of $90^{\circ} \mathrm{C}$ and 80 minutes gave a weight loss of only $1.8 \%$ indicating that the higher weight loss of $4.7 \%$ obtained with $0.75 \mathrm{M}$ dilute hydrochloric acid was due to the potency of hydrochloric acid as a leaching reagent.

Figure 4 shows the results of multistage leaching with $\mathrm{H}_{2} \mathrm{O}-\mathrm{HCl}-\mathrm{H}_{2} \mathrm{O}$ and $\mathrm{HCl}-\mathrm{H}_{2} \mathrm{O}-$ $\mathrm{H}_{2} \mathrm{O}$ sequences. The results obtained showed that the $\mathrm{H}_{2} \mathrm{O}-\mathrm{HCl}-\mathrm{H}_{2} \mathrm{O}$ leaching sequence gave the higher weight loss of $11.9 \%$ as against the $8.4 \%$ for the $\mathrm{HCl}-\mathrm{H}_{2} \mathrm{O}-\mathrm{H}_{2} \mathrm{O}$ sequence. This observation agrees with the conclusion of Adeleke et al. $(2011 ; 2013)$ that the $\mathrm{H}_{2} \mathrm{O}-\mathrm{Na}_{2} \mathrm{CO}_{3}-\mathrm{H}_{2} \mathrm{O}$ leaching sequence gave higher ash and sulphur reductions in LafiaObi coal than the $\mathrm{Na}_{2} \mathrm{CO}_{3}-\mathrm{H}_{2} \mathrm{O}-\mathrm{H}_{2} \mathrm{O}$ leaching sequence $[5,6]$. The reason for the higher leaching potency of the $\mathrm{H}_{2} \mathrm{O}-\mathrm{HCl}-\mathrm{H}_{2} \mathrm{O}$ sequence may be because in the route the preliminary water washing might have prepared the ore matrix for the subsequent acid leaching, making it more efficient and the last water washing might have helped in dissolving some of the soluble product of the acid leaching. Dilute acid leaching has been shown to be efficient leaching reagents. Alafara et al. (2005) have quantitatively evaluated leaching dissolution of Itakpe iron ore in hydrochloric acid [7]. Adeleke et al. (2012) developed a multistage dilute sulphuric acid leaching process route for upgrading low grade Itakpe iron ore for Ajaokuta Steel Plant [8]. Also, Alafara et al. (2007) applied microbial leaching in sulphuric acid to upgrade Itakpe iron ore for steel making [9]. 


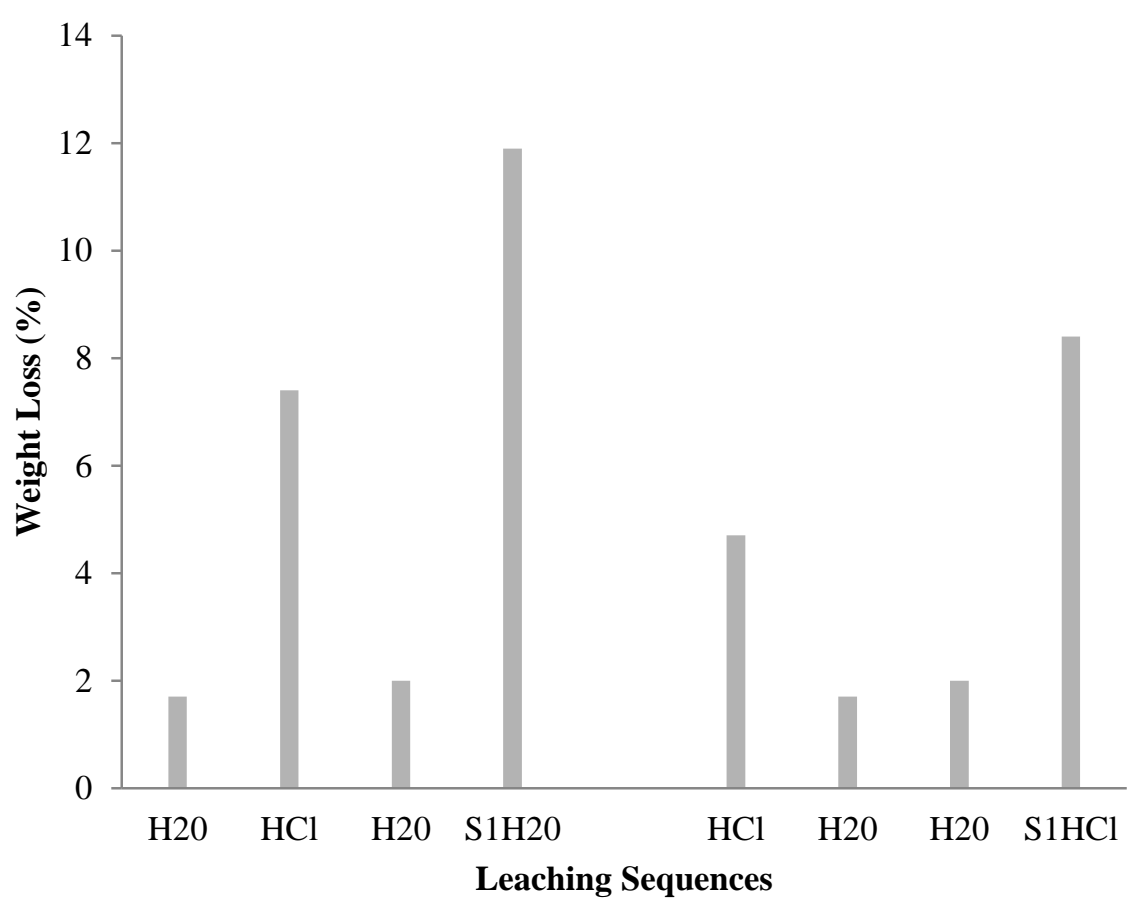

Figure 4. Multistage leaching of $\mathrm{KK}$ iron ore in sequences $\mathrm{H}_{2} \mathrm{O}-\mathrm{HCl}-\mathrm{H}_{2} \mathrm{O}$ and $\mathrm{HCl}-\mathrm{H}_{2} \mathrm{O}-\mathrm{H}_{2} \mathrm{O}$

KEY:

$\mathrm{S}_{1} \mathrm{H}_{2} \mathrm{O}=$ First stage $\mathrm{H}_{2} \mathrm{O}$ leaching in the $\mathrm{H}_{2} \mathrm{O}-\mathrm{HCl}-\mathrm{H}_{2} \mathrm{O}$ sequence

$\mathrm{S}_{1} \mathrm{HCl}=$ First stage dilute $\mathrm{HCl}$ leaching in the $\mathrm{HCl}-\mathrm{H}_{2} \mathrm{O}-\mathrm{H}_{2} \mathrm{O}$ sequence

Figure 4 further shows that the first stage dilute $\mathrm{HCl}$ leaching in the $\mathrm{HCl}-\mathrm{H}_{2} \mathrm{O}-\mathrm{H}_{2} \mathrm{O}$ leaching sequence yielded a higher weight loss than the first stage water leaching in the $\mathrm{H}_{2} \mathrm{O}-\mathrm{HCl}-\mathrm{H}_{2} \mathrm{O}$ route that however gave higher weight losses for its last two stages. The results thus showed that the preliminary water treatment with an intermediate acid leaching and a final water washing was more efficient than the first stage acid leaching followed by two stage water cleanings. The results agreed with the observation of Adeleke et al. (2012) on the dilute sulphuric acid leaching of Itakpe iron ore [8]. The higher leaching potency of the $\mathrm{H}_{2} \mathrm{O}-\mathrm{HCl}-\mathrm{H}_{2} \mathrm{O}$ leaching route may be because the initial water treatment cleaning makes the iron particles more responsive to the leaching reaction.
Figure 5 shows the effects of tabling and leaching on the chemical composition of the Koton Karfe iron ore. The results obtained showed that the tabling separation only increased the $\mathrm{Fe}$ content by about $5 \%$ but significantly reduced the contents of $\mathrm{Si}, \mathrm{Mn}$, $\mathrm{Ti}, \mathrm{K}, \mathrm{Na}, \mathrm{Ca}, \mathrm{Mg}$ and $\mathrm{P}$ by $40,34,7.7,12$, $16,13,16$ and $4.9 \%$ respectively (See series ATC of Figure 5). However, shaking tabling has no effect on the S content. On the other hand, dilute hydrochloric acid leaching was found to drastically increase the Fe content of the tabling concentrate by about $50 \%$ while it reduces its $\mathrm{Si}, \mathrm{Mn}, \mathrm{Ti}, \mathrm{K}, \mathrm{Na}, \mathrm{Ca}, \mathrm{P}$ and $\mathrm{S}$ by about 67, 100, 98, 98.8, 99.7, 98.6, 76 and $99.6 \%$ respectively (See series TLC of Figure 5). The results obtained thus showed that chemical leaching was far more efficient in 
leaching the iron ore than gravity concentration. It was further observed that gravity effect had low effectiveness for the concentration of $\mathrm{Fe}$ and $\mathrm{S}$ contents. The reduction in sulphur and phosphorous contents is significant as high sulphur and phosphorous contents in iron and steel causes brittleness. The alkali oxides are also un-desirable in the blast furnace iron making as they causes major blast furnace incidence like frozen hearth that adversely affect iron production [10].

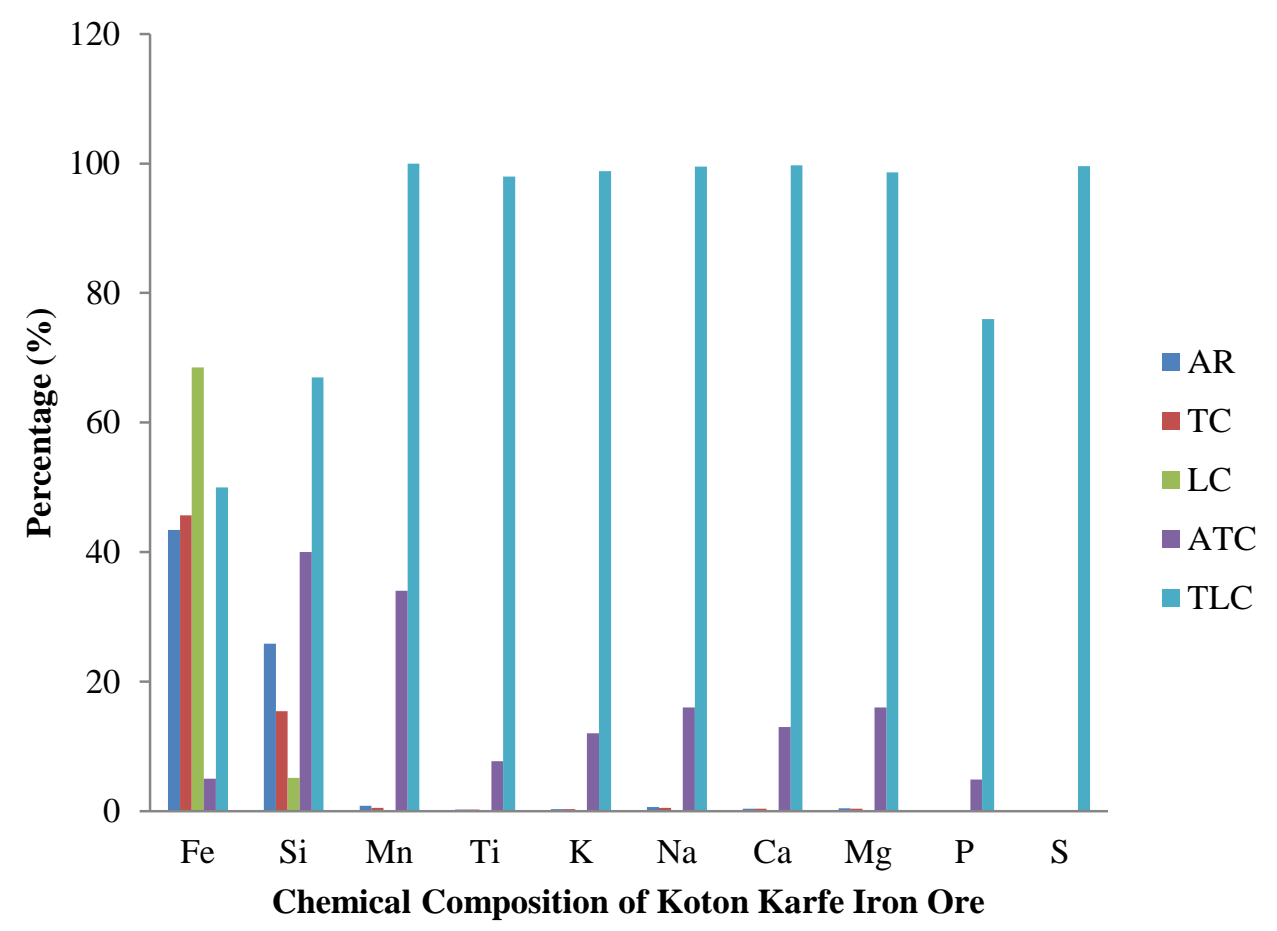

Figure 5. Effects of tabling and leaching concentrations on Koton Karfe iron ore

KEY:

$\mathrm{AR}=$ Percentage chemical composition of as-received ore

$\mathrm{TC}=$ Percentage chemical composition of tabled concentrate

$\mathrm{LC}=$ Percentage chemical composition of leached concentrate

ATC $=$ Percentage increase/decrease between AR and TC

TLC $=$ Percentage increase/decrease between TC and LC

Phosphorous content in steel is required to be low because it decreases ductility and notch impact toughness of steel, particularly in quenched and tempered higher-carbon steels. Phosphorous levels are normally controlled to low levels. It is a deleterious contaminant because it makes steel brittle, even at concentrations as low as $0.6 \%$ and it cannot be easily removed by fluxing or smelting, and so iron ores must generally be low in phosphorus before use. Sulphur also decreases ductility and notch impact toughness especially in the transverse direction. In addition, weldability decreases with increasing sulfur content [11]. Since the phosphorous and sulphur contents are low, 
and the pelletizing method to agglomerate ultrafine iron ores has been developed [12] the super concentrate of Koton Karfe iron ore can be used as input in the Midrex iron making.

The elemental analyses of as-received, tabled and leached concentrate are presented in Table 4. The results indicated that Koton Karfe iron ore can be upgraded to super concentrate of $68.5 \% \mathrm{Fe}$ from $43.5 \% \mathrm{Fe}$ by combination of shaking tabling and oven dilute hydrochloric atmospheric leaching which gives about $57 \%$ recovery of Fe. Figure
6 shows the light transmission micrographs of Koton Karfe iron ore as received, as concentrated after shaking tabling and leaching. The micrographs showed that the iron content of the concentrate was increased after the tabling pre-concentration and acid leaching. The results thus indicate that both tabling and leaching beneficiation successfully upgraded the medium grade iron ore by reducing the associated gangue minerals.

Table 4. Percentage elemental composition of iron ore

\begin{tabular}{lcccccccccc}
\hline $\begin{array}{c}\text { Ore } \\
\text { Concentrate }\end{array}$ & Fe & Si & Mn & Ti & K & Ca & Na & Mg & P & S \\
\hline As-Received & 43.45 & 25.85 & 0.8215 & 0.261 & 0.3272 & 0.6298 & 0.4092 & 0.4263 & 0.0246 & 0.0980 \\
As-Tabled & 45.66 & 15.43 & 0.5438 & 0.242 & 0.2875 & 0.5290 & 0.3542 & 0.3562 & 0.0234 & 0.0980 \\
As-Leached & 68.54 & 5.14 & 0.0000 & 0.004 & 0.0035 & 0.0024 & 0.0011 & 0.0050 & 0.0056 & 0.0004 \\
\hline
\end{tabular}

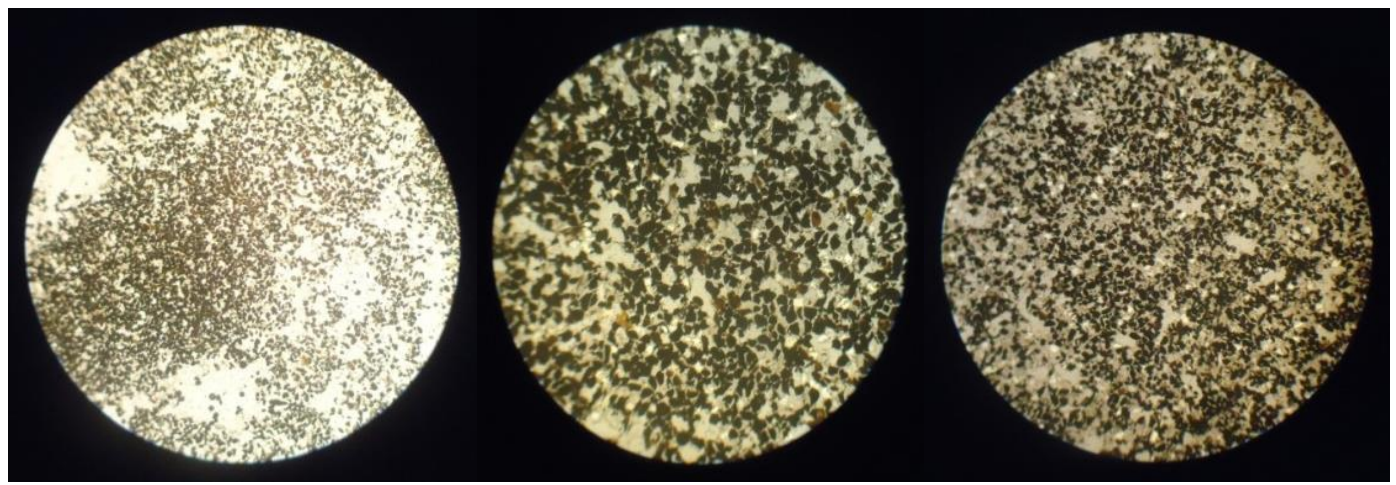
a) As-received
b) Tabling concentrate
c) Leach sample

Figure 6. Photomicrograph of $75 \mu \mathrm{m}$ sieve size (Mag. $\times 400)$

\section{Conclusion}

The Koton Karfe iron ore has been successfully upgraded to a super-concentrate from an initial iron concentration of about 43.5 to 45.7 and $68.5 \%$ by shaking tabling and oven dilute hydrochloric atmospheric leaching indicating 5.1 and $49.9 \%$ upgrades, respectively. Furthermore, the contents of alkali elements sodium and potassium and phosphorus/sulphur that are deleterious in iron making were drastically reduced rendering the iron ore more suitable for both blast furnace and Midrex direct iron making processes. In addition, silica, the highest mineral gangue present was reduced from $25.8 \%$ to about $5.5 \%$ translating to about $80 \%$ reduction. The availability of a pelletizing method for agglomerating ultrafine iron ores makes the product of this work a possible input in the Midrex iron making. 


\section{References}

[1] Lee Tan Yaa Chi-Lung, (1970) Abundance of the chemical elements in the earth's crust. Int. Geology Rev., 12, 778.

[2] Journal of National iron ore Mining Company Limited, (2001) Itakpe, Nigeria, 3-9.

[3] Yusfin, Y.S., Chernousov, P.I., Garten, V., Karpov, Y.A., Petelin, A.L. (1999) The role of alkali's and conserving resources in blast-furnace smelting. Metallurgist, 43, 54-58.

[4] Uwadiale, O.O. Beneficiation studies of Agbaja iron ore, (1984), PhD Thesis, Department of Pure and Applied Chemistry, University of Strathclyde, Glascow, Scotland.

[5] Adeleke, A.A., Ibitoye, S.A., Afonja, A.A. (2013) Multistage caustic leaching de-sulphurization of a high sulphur coal. Petroleum and Coal, 55 (2), 113-118.

[6] Adeleke, A.A., Ibitoye, S.A., Afonja, A.A., Chagga, M.M. (2011) Multistage caustic leaching de-ashing of Nigerian Lafia-Obi coal. Petroleum and Coal, 53 (4), 259-265.

[7] Alafara, A.B., Adekola, F.A., Folashade, A.O. (2005) Quantitative leaching of a Nigerian iron ore in hydrochloric acid. Journal of Applied Science and Environmental Management, 9 (3) 15-20.
[8] Lee Tan Yaa Chi-Lung, (1970) Abundance of the chemical elements in the earth's crust. Int. Geology Rev., 12, 778.

[9] Adeleke, A.A., Ibitoye, S.A., Enajero, M.O., Popoola, A.P.I. (2012) Multi-stage dilute acid leaching of a low grade iron ore. Journal of Engineering Research, 17 (4), 15-21.

[10] Alafara, A.B., Adekola, F.A., Lawal, A.J. (2007) Investigation of chemical leaching of iron ore in sulphuric acid. Journal of Applied Science and Environmental Management, 11 (1), 39-44.

[11] Poos, A. (1992) Future requirements for blast furnace coke quality. Cokemaking International, 4, 29-30.

[12] Mitra, S.K. (2013), Iron ore testing and analysis (www.mitrask.com/ironore-test ing-analysis.html. Accessed: $16^{\text {th }}$ September, 2013)

[13] Kumar, S., Srinivasan, T.M. (2013), Sintering and pelletisation of Indian iron ores (www.iim-delhi.com/.../04 Sintering PelletisingIndianIronOre_FerroGreen..... Accessed: $16^{\text {th }}$ September, 2013) 